\title{
Idiopathic Pulmonary Fibrosis: Best Practice in Monitoring and Managing a Relentless Fibrotic Disease
}

\author{
Wim A. Wuyts ${ }^{a}$ Marlies Wijsenbeek ${ }^{b}$ Benjamin Bondue ${ }^{c}$ \\ Demosthenes Bouros $^{d}$ Paul Bresser ${ }^{\mathrm{e}}$ Carlos Robalo Cordeiro ${ }^{f}$ Ole Hilberg ${ }^{g}$ \\ Jesper Magnusson $^{\mathrm{h}}$ Effrosyni D. Manali ${ }^{i} \quad$ António Morais $^{j} \quad$ Spyridon Papiris $^{\mathrm{i}}$ \\ Saher Shaker ${ }^{k}$ Marcel Veltkamp' Elisabeth Bendstrup ${ }^{m}$
}

\begin{abstract}
${ }^{a}$ Department of Respiratory Diseases, Unit for Interstitial Lung Diseases, University Hospitals Leuven, Leuven, Belgium; ${ }^{b}$ Department of Respiratory Medicine, Erasmus MC, University Medical Centre, Rotterdam, The Netherlands; ' ${ }^{\text {Department }}$ of Pneumology, Hôpital Erasme, Université libre de Bruxelles, Brussels, Belgium; ${ }^{\mathrm{d}}$ First Academic Department of Pneumonology, Interstitial Lung Diseases Unit, Department of Medicine, National and Kapodistrian University of Athens, Athens, Greece; e Department of Respiratory Medicine, Onze Lieve Vrouwe Gasthuis, Amsterdam, The Netherlands; ${ }^{f}$ Department of Pneumology, Coimbra University Hospital, Coimbra, Portugal; ${ }^{9}$ Department of Respiratory Medicine and Allergology, Aarhus University Hospital, Aarhus, Denmark; h Department of Internal Medicine/Respiratory Medicine and Allergology, Institute of Medicine, University of Gothenburg, Gothenburg, Sweden; '2nd Pulmonary Medicine Department, General University Hospital "Attikon," Medical School, National and Kapodistrian University of Athens, Athens, Greece; 'Department of Pulmonology, Hospital de São João, Porto, Portugal; ' ${ }^{\mathrm{K} H e r l e v}$ and Gentofte University Hospital, Copenhagen, Denmark;

'Department of Pulmonology ILD Center of Excellence, St. Antonius Hospital, Nieuwegein, The Netherlands;

${ }^{m}$ Center for Rare Lung Diseases, Department of Respiratory Diseases and Allergy, Aarhus University Hospital, Aarhus, Denmark
\end{abstract}

\section{Keywords}

Nintedanib · Pirfenidone · Interstitial lung disease .

Therapeutics $\cdot$ Treatment $\cdot$ Mortality

\begin{abstract}
Idiopathic pulmonary fibrosis (IPF) is a fibrosing interstitial lung disease that is, by definition, progressive. Progression of IPF is reflected by a decline in lung function, worsening of dyspnea and exercise capacity, and deterioration in healthrelated quality of life. In the short term, the course of disease
\end{abstract}

for an individual patient is impossible to predict. A period of relative stability in forced vital capacity (FVC) does not mean that FVC will remain stable in the near future. Frequent monitoring using multiple assessments, not limited to pulmonary function tests, is important to evaluate disease progression in individual patients and ensure that patients are offered appropriate care. Optimal management of IPF requires a multidimensional approach, including both pharmacological therapy to slow decline in lung function and supportive care to preserve patients' quality of life.

(C) 2019 The Author(s)

Published by S. Karger AG, Basel

\section{KARGER}

E-Mail karger@karger.com www.karger.com/res

\section{(c) 2019 The Author(s)}

Published by S. Karger AG, Basel

Karger

Open access

This article is licensed under the Creative Commons AttributionNonCommercial-NoDerivatives 4.0 International License (CC BYNC-ND) (http://www.karger.com/Services/OpenAccessLicense). Usage and distribution for commercial purposes as well as any distribution of modified material requires written permission.
Wim A. Wuyts

Department of Respiratory Diseases

Unit for Interstitial Lung Diseases, University Hospitals Leuven

Herestraat 49, BE-3000 Leuven (Belgium)

E-Mail wim.wuyts@uzleuven.be 


\section{Introduction}

Idiopathic pulmonary fibrosis (IPF) is a chronic progressive fibrosing interstitial lung disease (ILD) characterized by the presence of a usual interstitial pneumonia pattern on high-resolution computed tomography (HRCT) [1]. Diagnosis is recommended to be made in the context of a multidisciplinary discussion. IPF tends to affect adults in their sixties or seventies who have a history of smoking and is more commonly observed in men than in women [2-5]. Patients typically present with chronic dyspnea and a dry nonproductive cough and have "Velcro"-like bibasilar crackles on chest auscultation [1, $3]$. The reported incidence and prevalence of IPF vary widely depending on the methodology used to define cases, but its incidence in North America and Europe, based on a systematic review of population-based studies, has been conservatively estimated as between 3 and 9 cases per 100,000 persons per year [6].

The prevailing hypothesis for the pathogenesis of IPF is that the disease is caused by persistent micro-injury to the alveolar epithelium combined with an abnormal repair process. Continued replacement of alveolar tissue with fibrotic lesions distorts the lung architecture, resulting in a reduction in lung volume, impaired gas exchange, and ultimately in death [7]. Median survival after diagnosis of IPF is approximately $3-4$ years $[2,8,9]$. However, the clinical course of IPF is variable between patients [10]. Some patients die shortly after diagnosis, while others experience a slower decline over time, and some show periods of clinical stability interspersed with episodes of rap- id respiratory deterioration known as acute exacerbations [11]. Acute exacerbations are devastating events associated with very high mortality; in-hospital mortality following an acute exacerbation is estimated to be over $50 \%$ [11]. Although acute exacerbations are more common in patients with advanced lung function impairment, they can occur at any time, including in patients with preserved lung function $[12,13]$.

In this review, we will discuss the manifestations of disease progression in patients with IPF, how disease progression can be evaluated, and the importance of taking a multifaceted and individualized approach to the monitoring and management of IPF. This article is based on discussions held at a meeting attended by the authors in June 2017, as well as a review of the scientific literature.

\section{Progression of IPF}

IPF is, by definition, a progressive disease [1]. Progression of IPF is typically reflected in a decline in forced vital capacity (FVC), worsening of dyspnea, a reduction in exercise capacity, and deterioration in health-related quality of life (HRQL) $[5,14,15]$. Data from clinical trials suggest that in patients with mild or moderate lung function impairment at baseline, the decline in FVC in patients who receive placebo is approximately $150-200 \mathrm{~mL}$ over 1 year (Fig. 1) [16]. Decline in FVC is a strong predictor of mortality in patients with IPF. In a pooled analysis of data from the placebo groups of the TOMORROW, INPULSIS, CAPACITY, and ASCEND trials, patients who had
Fig. 1. Lung function decline in patients with IPF treated with placebo in Phase II and III clinical trials [16]. Red dots denote the mean or median change from baseline in FVC or VC in the placebo groups of Phase II and III clinical trials in patients with IPF. The black line denotes the mean decline in FVC in healthy subjects aged 60 years based on FVC measurements taken between 1987-1989, 1990-1992, and 20112013 [87]. Reproduced with permission of the ${ }^{(}$ERS 2019 [16]. This material has not been reviewed prior to release; therefore, the European Respiratory Society may not be responsible for any errors, omissions, or inaccuracies, or for any consequences arising there from, in the content. FVC, forced vital capacity; IPF, idiopathic pulmonary fibrosis.

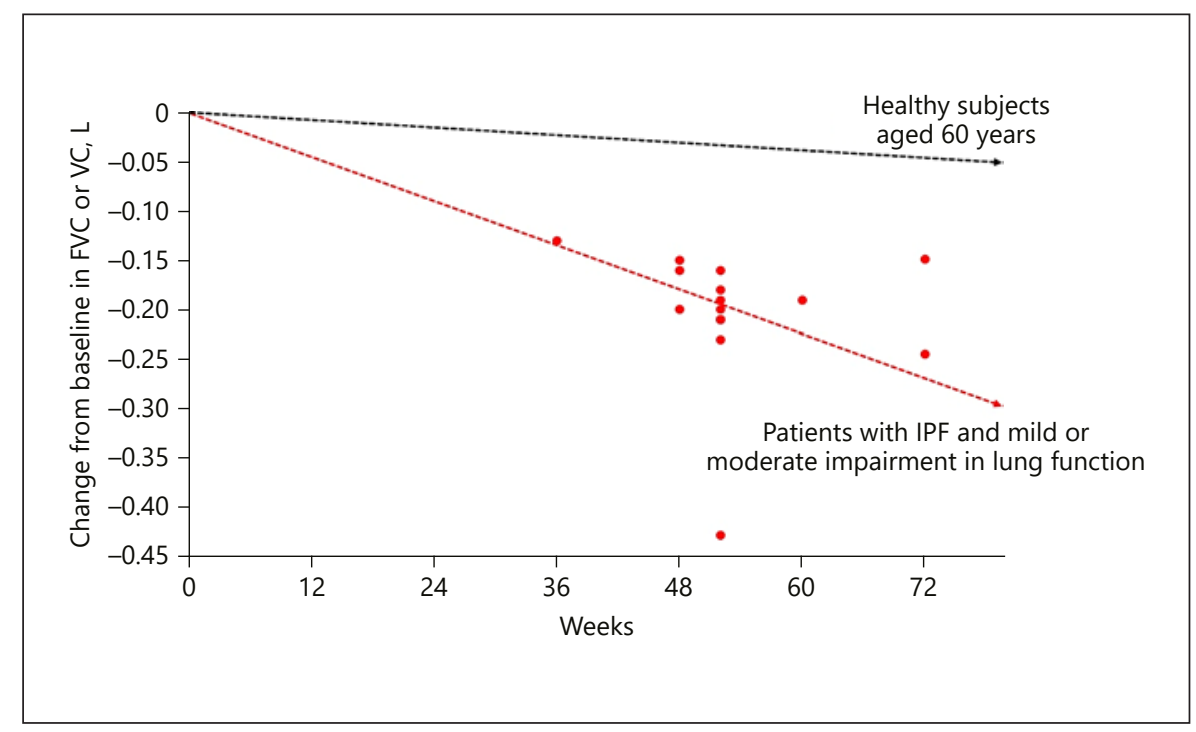


an FVC decline $\geq 10$ to $<15 \%$ predicted had a more than two-fold greater risk of mortality during the trials than patients who had an FVC decline $<5 \%$ predicted (Fig. 2) [17]. Other studies have shown even greater risks of mortality associated with decline in $\mathrm{FVC} \geq 10 \%$ predicted [12]. Patients with low FVC, or with documented decline in FVC, are also more likely to experience an acute exacerbation $[12,18]$.

While these data from clinical trials are useful for characterizing the progression of IPF at a population level, for an individual patient, the situation is much more complex. At present, there is no means of making an accurate prediction of disease course for an individual patient. Prior rate of change in FVC appears to be a poor predictor of subsequent change in FVC (Fig. 3) [19]. In the INPULSIS trials, placebo-treated patients with well-preserved FVC (FVC $>90 \%$ predicted) at baseline had almost exactly the same decline in FVC over 1 year as patients with less well-preserved FVC (-225 vs. $-224 \mathrm{~mL} /$ year, respectively) [13]. Preservation of FVC in patients with IPF should not be regarded as indicating that FVC will remain stable in the future. A period of stability in FVC does not mean that the disease is not progressing at a subclinical level or that the patient is not at risk of an acute exacerbation or death. A seminal study found that even in patients with stable FVC over 6 months, median survival was only 3 years [20]. Thus, it is important that measures other than FVC are taken into account in the evaluation of disease progression in an individual patient.

Gas exchange, measured by the diffusing capacity of the lungs for carbon monoxide (DLco), is reduced in patients with IPF and declines as the disease progresses [14, $21]$. A decline in DLco $>15 \%$ predicted over 6-12 months is associated with a significantly increased risk of mortality in patients with IPF $[5,22]$. Difficulties in standardizing measurements across centers make DLco a chal-

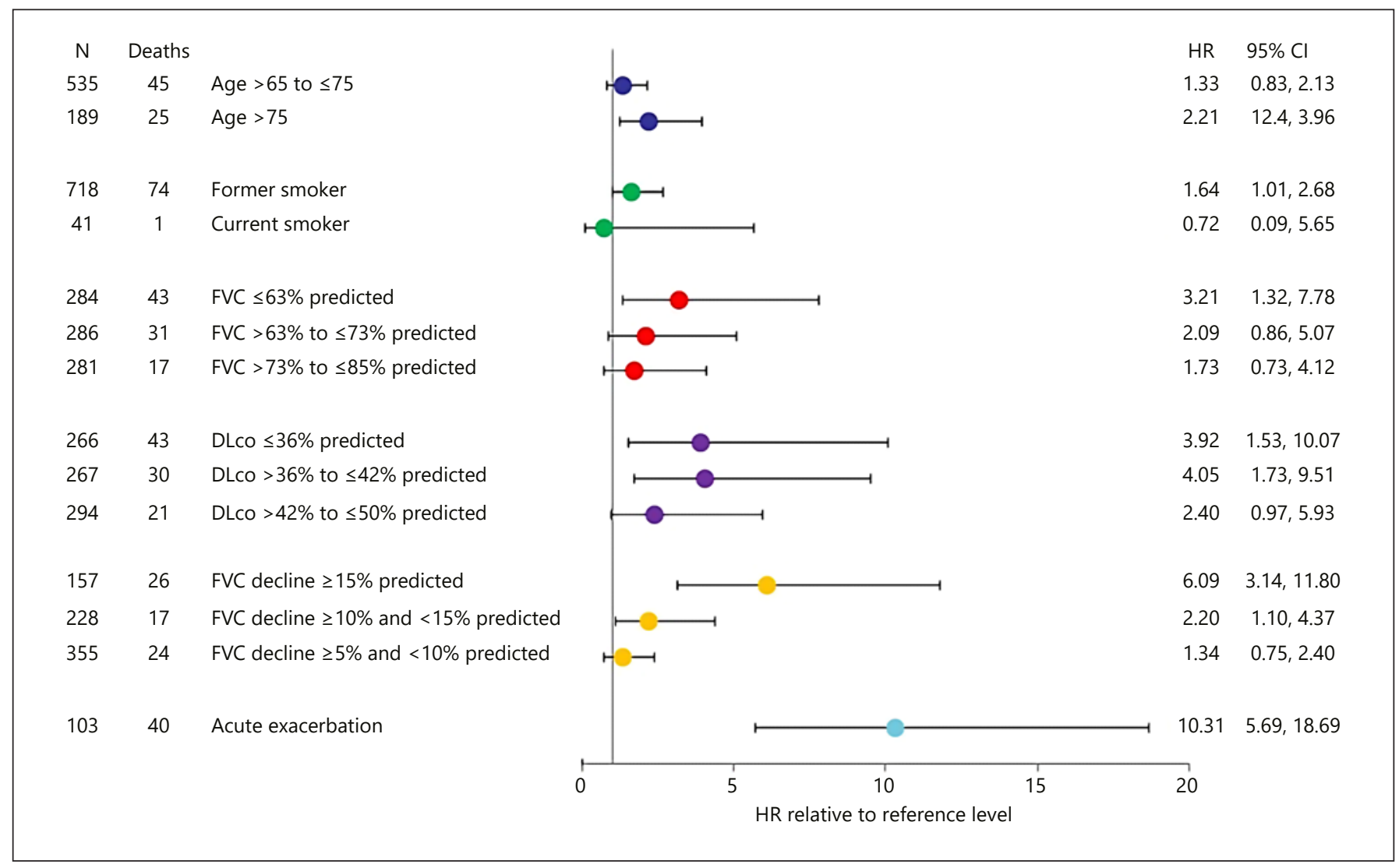

Fig. 2. Risk of mortality in patients treated with placebo in the TOMORROW, INPULSIS, CAPACITY, and ASCEND trials in subgroups by baseline variables, decline in FVC, and acute exacerbations (adapted from [17]). Comparisons were made to reference levels: age $<65$ years, never smoker, FVC $>85 \%$ predicted, DLco $>$
$50 \%$ predicted, FVC decline $<5 \%$ predicted, no acute exacerbation. Reprinted with permission of the American Thoracic Society. Copyright ${ }^{\circledR} 2019$ American Thoracic Society [17]. FVC, forced vital capacity.
Best Practice in Monitoring and Managing IPF 

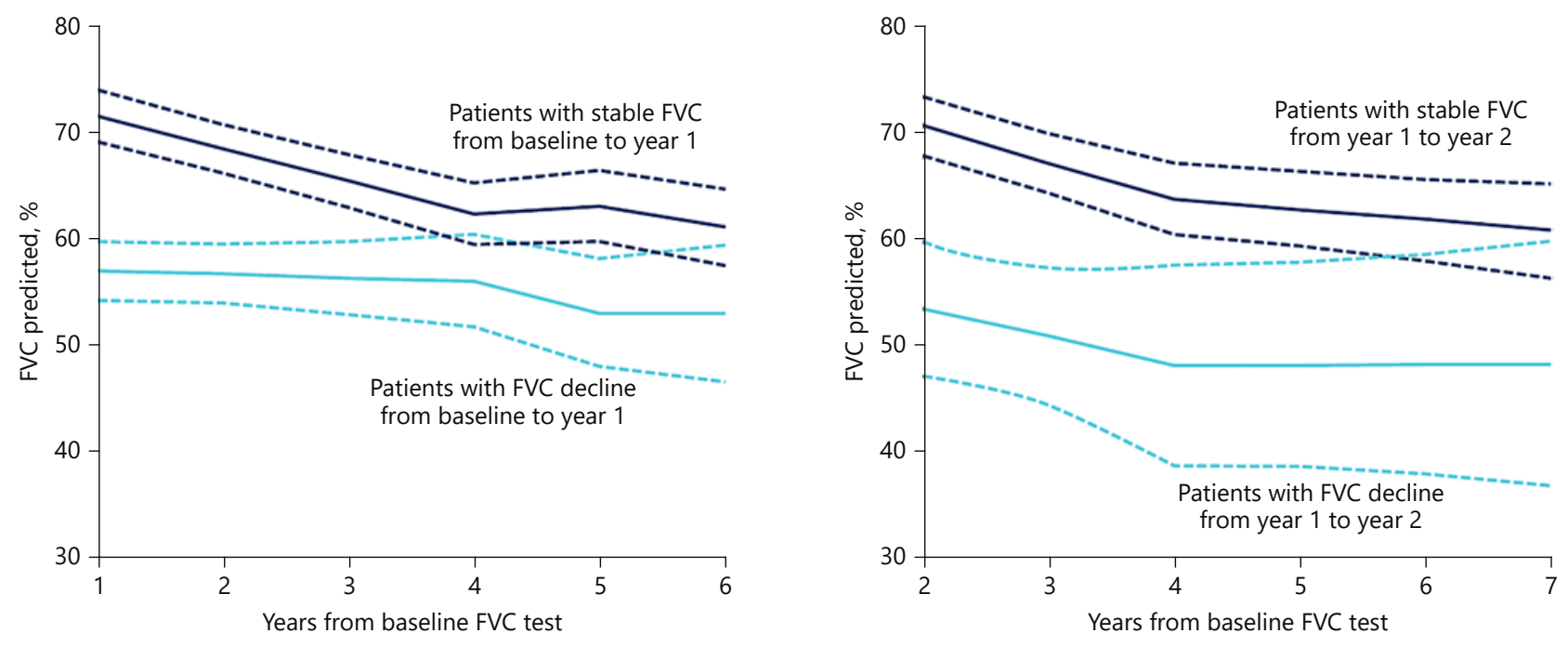

Fig. 3. Trajectory of FVC following stability or decline in previous year (adapted from [19]). Mixed-models analysis of trend in FVC. Solid lines indicate mean FVC; dashed lines indicate 95\% CI. Reprinted from [19]. Copyright (2019) with permission from the American College of Chest Physicians; permission conveyed through Copyright Clearance Center, Inc. FVC, forced vital capacity.

lenging end point to use in clinical trials, but in clinical practice, it is a useful tool for assessing disease progression in an individual patient.

The functional deterioration that occurs as IPF progresses is reflected in a diminishing of exercise capacity. In a study of 748 patients, a reduction in the distance walked during a 6 -min walk test of $>50$ m over 24 weeks was associated with a nearly three-fold increase in mortality over the following year [23]. Oxygen desaturation during exercise (reduction of $>10 \%$ from baseline) has also been associated with a significantly increased risk of mortality [24]. A requirement for supplemental oxygen, initially during exertion and then later also at rest, is a marker of advanced disease in patients with IPF and a strong predictor of mortality $[21,22,25,26]$. In a realworld cohort of 167 patients with IPF, median survival after initiation of oxygen therapy was $<18$ months, compared with approximately 49 months for patients not using supplemental oxygen [21].

The symptoms of IPF, particularly cough and dyspnea, invariably worsen as the disease progresses [14, 27]. Cough has been shown to be an independent predictor of disease progression (defined as a decline in FVC $\geq 10 \%$ predicted, decline in DLco $\geq 15 \%$ predicted, lung transplantation, or death) in the following 6 months [28]. An increase in the severity of dyspnea is also a predictor of mortality [22, 29]. Cough and dyspnea are major determinants of HRQL among patients with IPF [14, 27, 30]. As IPF progresses, worsening of symptoms makes it difficult for patients to perform tasks requiring even mild exertion, with impacts on many aspects of patients' lives including family, social participation, and employment $[27,31]$. Thus, for an individual patient, worsening of symptoms can be the most debilitating aspect of the progression of the disease.

There is increasing evidence that the extent of fibrosis on HRCT, and of specific features evident on HRCT such as reticular patterns with architectural distortion and vessel-related structures, and changes in these over time are predictors of mortality in patients with IPF [32-34]. However, in clinical practice, it is currently not possible to use changes in HRCT scans as a means of assessing disease progression. More research is needed to validate computerized scoring systems against outcomes. At present, there is no consensus as to when repeat HRCT scans should be performed in the monitoring of patients with IPF. The identification and validation of genetic and molecular biomarkers that predict disease progression is also an active area of research [35-38], but the integration of biomarkers into clinical practice remains some time away.

Given the shortcomings of single assessments as predictors of mortality in patients with IPF, multivariate 
models have been developed, including the GAP (gender, age, physiology) index and staging system [39], the composite physiologic index [40], and the risk stratification score [41]. However, none of these provides an accurate prediction of disease course for an individual patient, and none has been widely implemented in clinical practice.

\section{Monitoring Patients with IPF}

Frequent monitoring is essential to evaluate disease progression in patients with IPF and so inform therapeutic decisions and patient counseling. Pulmonary function tests (PFTs) are a vital part of patient monitoring, but given that FVC decline is not the only indicator of disease progression in patients with IPF, follow-up assessments should not be limited to PFTs. While there is little evidence available to define the optimal interval between clinic visits, we regard visits with assessments of FVC and DLco every 3-4 months as reasonable for monitoring disease progression and for maintaining a good relationship with the patient. A disadvantage of performing PFTs at this frequency is that given the noise in FVC measurements, a number of measurements may be needed to detect a decline in FVC, leading to a significant lag time before FVC decline is identified and delays to decisions on treatment. More frequent monitoring of FVC using home spirometry may enable earlier detection of FVC decline and acute exacerbations [42-44], but its utility in everyday practice has yet to be established. In interpreting measurements of FVC and DLco, clinicians should be mindful of the potential confounding effects of concomitant emphysema; in patients with an extent of emphyse$\mathrm{ma} \geq 15 \%$, FVC may not be a reliable measure for assessing disease progression [45].

Symptoms and HRQL can be assessed at every clinical visit through open-ended questions and the use of questionnaires [46, 47]. However, no short, disease-specific questionnaire to assess the overall severity and impact of the disease has been validated in patients with IPF. The severity and impact of dyspnea can be difficult to determine without an understanding of the level of activity normally undertaken by the patient; exertional dyspnea in a patient who is elderly and infirm is not comparable to that in an individual who has remained active. Patients who report only mild dyspnea may have reduced the severity of their dyspnea by reducing their mobility. The use of quantitative metrics such as the University of California San Diego Shortness of Breath Questionnaire [48], Medical Research Council dyspnea scale [49], or Borg

Best Practice in Monitoring and Managing IPF scale [50] can be of value in the assessment of changes in dyspnea as IPF progresses.

The 6-min walk test is a simple test that can be valuable in the assessment and follow-up of patients with IPF. If serial tests are used, it is important that the same methodology is used for all tests, including consistency in the delivery of supplemental oxygen (else differences in the provision of supplemental oxygen should be considered in the interpretation of test results) [51, 52]. Training effects and the potential impact of comorbidities should also be taken into account in the interpretation of followup test results. Oxygen saturation should be measured during the test and into the recovery period. An oxygen desaturation $<88 \%$ during exercise is generally used as a guideline for prescribing supplemental oxygen. Oxygen saturation at rest should be measured at every clinic visit and the results considered in deciding on patient care.

\section{Slowing the Progression of IPF}

All patients with IPF should be informed about access to treatments that slow disease progression. Two antifibrotic drugs, nintedanib [53] and pirfenidone [54], have been approved for the treatment of IPF. In large, placebocontrolled trials in patients with IPF and mild or moderate impairment in FVC at baseline, nintedanib [55] and pirfenidone [56] each reduced decline in FVC by approximately $50 \%$ over 1 year. Further, there was some evidence that these therapies reduced the risk of acute respiratory worsenings $[18,57]$. Treatment guidelines issued by ATS/ERS/JRS/ALAT in July 2015 provided conditional recommendations for the use of nintedanib and pirfenidone in patients with IPF, recognizing that different choices will be appropriate for individual patients and that clinicians must help patients arrive at a decision about their management [58]. These recommendations are echoed in country-specific treatment guidelines and position statements authored by regional experts [5963]. Importantly, data from clinical trials showed that nintedanib and pirfenidone had the same effect on FVC decline across the spectrum of baseline FVC investigated (FVC $>50 \%$ predicted) $[13,64-67]$. These data, combined with the unpredictable nature of disease progression in patients with IPF, and the fact that FVC is not the only indicator of disease severity or progression argue against a "watch and wait" approach to treatment.

The latest international treatment guidelines also provided a conditional recommendation for the use of anti-acid therapy in patients with IPF and asymptom- 


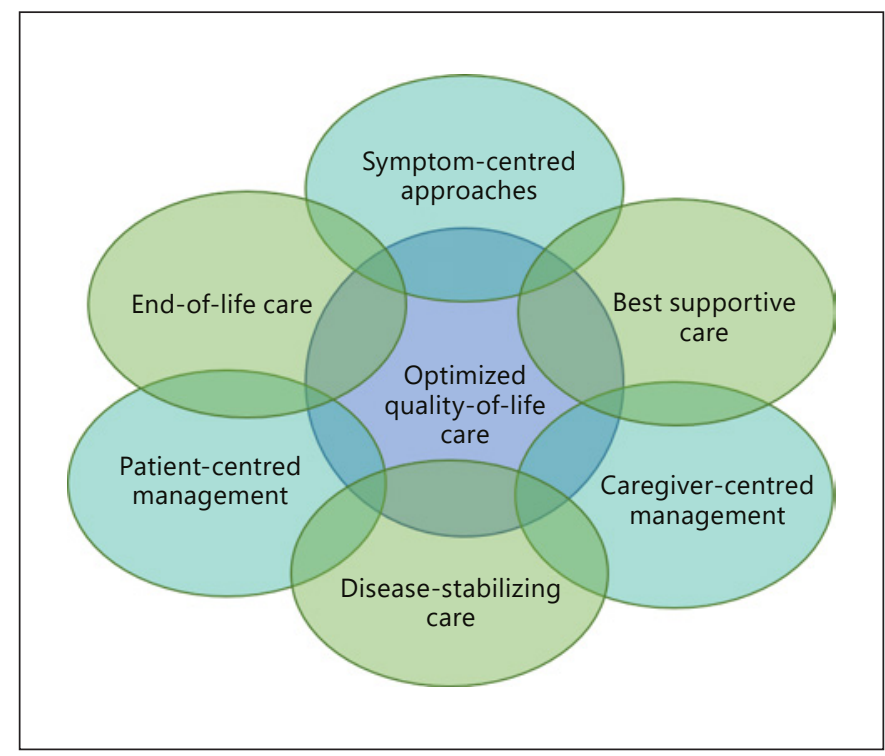

Fig. 4. A multifaceted approach to managing patients with IPF (adapted from [88]). Reprinted from [88]. Copyright (2019) with permission from Elsevier; permission conveyed through Copyright Clearance Center, Inc.

atic gastroesophageal reflux disease, based on very lowquality evidence [58]; however, in the absence of randomized controlled trials, the risk:benefit of anti-acid medications in patients with IPF remains unknown [68, 69]. All other pharmacological therapies that have been used in the treatment of IPF, including $\mathrm{N}$-acetylcysteine, received strong or conditional recommendations against their use [58]. Lung transplantation is an option for a minority of patients with IPF, with guidelines recommending that patients be evaluated for transplant at an early stage [70].

\section{Symptom Management and Supportive Care}

Symptom management and supportive care are important elements of the management of IPF (Fig. 4). Symptom control presents great challenges to clinicians, as the dyspnea, cough, and fatigue associated with IPF are difficult to manage, with little evidence available to inform therapeutic decision-making. Although oral corticosteroids and opiates are sometimes used to relieve cough and dyspnea, the benefits of these therapies have not been established $[71,72]$. Supplemental oxygen is recommended in international treatment guidelines for patients with IPF and clinically significant resting hypoxemia [58]. A recent randomized study showed that supplemental oxygen provided benefits on HRQL in patients with ILD and exertional hypoxia [73], but more evidence is needed on its optimal use in patients with ILD [74]. Pulmonary rehabilitation is recommended in treatment guidelines [75] and has been shown in short-term studies to provide improvements in exercise capacity, dyspnea, and quality of life in patients with IPF [76].

The identification and management of comorbid conditions is an important part of optimizing outcomes and HRQL in patients with IPF $[77,78]$. Many patients with IPF have comorbid respiratory and nonrespiratory conditions that complicate their disease, such as pulmonary hypertension, chronic obstructive pulmonary disease, emphysema, gastroesophageal reflux disease, cardiovascular disease, obstructive sleep apnea, and depression.

\section{Patient Education and Communication}

A lack of appropriate information remains a challenge for patients with IPF and their caregivers $[79,80]$. Much of the information about IPF provided on the Internet is outdated and inaccurate [81]. Although patients require information at the time of diagnosis, some issues may be better discussed at a later stage, according to the needs of the patient [82]. In addition to general information, patients value practical advice on how to manage their disease and maximize their quality of life [83]. It is essential that clinicians explain to patients and their caregivers that IPF is an intrinsically progressive disease so that they understand the value of taking therapies that slow disease progression even though their disease will continue to progress and their symptoms are not relieved. In particular, patients should be made aware that a history of relatively stable disease does not rule out a significant decline in lung function in the near future or the occurrence of an acute exacerbation. A structured, patient-centered communication approach is recommended to ensure that patients are supported in coming to an informed decision about how their disease should be managed [84].

Supportive/palliative care aims to improve or maintain HRQL as far as possible by relieving symptoms and providing support to patients and their caregivers to help them manage the impact of the disease and reduce fears about the future [85]. Supportive care may be provided on a one-to-one basis, via patient support groups, as part of pulmonary rehabilitation programs, or within 
an in-patient setting [85]. Specialist nurses can play a key role in providing advice and support to patients. Given the unpredictable course of IPF, supportive care should be integrated into discussions with patients and their caregivers at an early stage $[85,86]$. End-of-life planning can be a difficult issue for patients and their families to discuss, and the timing and volume of information should be individualized to the needs of the patient $[87,88]$.

\section{Conclusions}

IPF is an intrinsically progressive disease with a poor prognosis. Although predictors of disease progression and mortality have been identified in clinical trials and epidemiological studies, the course of disease for an individual patient remains impossible to predict. Progression of IPF is reflected by a decline in FVC, worsening of symptoms and exercise capacity, and deterioration in HRQL, but significant variability is observed between patients. A period of relative stability in FVC should not be interpreted as meaning that the disease is not progressing at a subclinical level or that FVC will remain stable in the near future. Frequent monitoring using multiple assessments including PFTs and measurements of functional capacity, symptoms, and HRQL is important to evaluate disease progression in individual patients and ensure that patients are offered appropriate care throughout the course of their disease. Optimal management of IPF requires a multidimensional approach, including both pharmacological therapy and supportive care.

\section{Acknowledgments}

Medical writing assistance, supported financially by Boehringer Ingelheim, was provided by Julie Fleming and Wendy Morris of FleishmanHillard Fishburn, London, UK, during the preparation of this article. The authors were fully responsible for all content and editorial decisions, were involved at all stages of manuscript development, and have approved the final version of the manuscript, which reflects the authors' interpretation and conclusions.

\section{Disclosure Statement}

This article was based on discussions held at a meeting supported by Boehringer Ingelheim. In addition, W.W. has received research grants from Boehringer Ingelheim and Roche and personal fees from Boehringer Ingelheim. M.W. has received research grants and other support from Boehringer Ingelheim and Roche and other support from Galapagos. B.B. and D.B. have received research grants and personal fees from Boehringer Ingelheim and Roche. O.H. has received research grants from Boehringer Ingelheim and personal fees from Roche. J.M. has received personal fees from Boehringer Ingelheim and Roche. E.D.M. has received research grants from Boehringer Ingelheim and Roche. S.P. has received research grants from Boehringer Ingelheim and Roche. S.S. has received personal fees and nonfinancial support from Boehringer Ingelheim and Roche. E.B. has received research grants and personal fees from Boehringer Ingelheim and Roche.

\section{Funding Sources}

The page processing charges for this article would be paid by Boehringer Ingelheim.

\section{Author Contributions}

All authors contributed to the interpretation of the data and to the content of the article and have approved the final version.

\section{References}

1 Raghu G, Remy-Jardin M, Myers JL, Richeldi L, Ryerson CJ, Lederer DJ, et al.; American Thoracic Society, European Respiratory Society, Japanese Respiratory Society, and Latin American Thoracic Society. Diagnosis of idiopathic pulmonary fibrosis. An official ATS/ ERS/JRS/ALAT clinical practice guideline. Am J Respir Crit Care Med. 2018 Sep; 198(5):e44-68.

2 Hyldgaard C, Hilberg O, Bendstrup E. How does comorbidity influence survival in idiopathic pulmonary fibrosis? Respir Med. 2014 Apr;108(4):647-53.

3 Behr J, Kreuter M, Hoeper MM, Wirtz H, Klotsche J, Koschel D, et al. Management of patients with idiopathic pulmonary fibrosis in clinical practice: the INSIGHTS-IPF registry. Eur Respir J. 2015 Jul;46(1):186-96.
4 Wuyts WA, Dahlqvist C, Slabbynck H, Schlesser M, Gusbin N, Compere C, et al. Longitudinal clinical outcomes in a real-world population of patients with idiopathic pulmonary fibrosis: the PROOF registry. Respir Res. 2019 Oct;20(1):231.

5 Doubková M, Švancara J, Svoboda M, Šterclová M, Bartoš V, Plačková M, et al. EMPIRE Registry, Czech Part: impact of demographics, pulmonary function and HRCT on survival and clinical course in idiopathic pulmonary fibrosis. Clin Respir J. 2018 Apr; 12(4):1526-35.

6 Hutchinson J, Fogarty A, Hubbard R, McKeever T. Global incidence and mortality of idiopathic pulmonary fibrosis: a systematic review. Eur Respir J. 2015 Sep;46(3):795-806.
7 Wuyts WA, Agostini C, Antoniou KM, Bouros $\mathrm{D}$, Chambers RC, Cottin V, et al. The pathogenesis of pulmonary fibrosis: a moving target. Eur Respir J. 2013 May;41(5):1207-18.

8 Raghu G, Chen SY, Yeh WS, Maroni B, Li Q, Lee $\mathrm{YC}$, et al. Idiopathic pulmonary fibrosis in US Medicare beneficiaries aged 65 years and older: incidence, prevalence, and survival, 2001-11. Lancet Respir Med. 2014 Jul;2(7): $566-72$.

9 Strongman H, Kausar I, Maher TM. Incidence, prevalence, and survival of patients with idiopathic pulmonary fibrosis in the UK. Adv Ther. 2018 May;35(5):724-36.

10 Ley B, Collard HR, King TE Jr. Clinical course and prediction of survival in idiopathic pulmonary fibrosis. Am J Respir Crit Care Med. 2011 Feb;183(4):431-40. 
11 Collard HR, Ryerson CJ, Corte TJ, Jenkins G, Kondoh Y, Lederer DJ, et al. Acute exacerbation of idiopathic pulmonary fibrosis. An international working group report. Am J Respir Crit Care Med. 2016 Aug;194(3):26575.

12 Reichmann WM, Yu YF, Macaulay D, Wu EQ, Nathan SD. Change in forced vital capacity and associated subsequent outcomes in patients with newly diagnosed idiopathic pulmonary fibrosis. BMC Pulm Med. 2015 Dec;15(1):167.

13 Kolb M, Richeldi L, Behr J, Maher TM, Tang W, Stowasser S, et al. Nintedanib in patients with idiopathic pulmonary fibrosis and preserved lung volume. Thorax. 2017 Apr;72(4): 340-6.

14 Glaspole IN, Chapman SA, Cooper WA, Ellis SJ, Goh NS, Hopkins PM, et al. Health-related quality of life in idiopathic pulmonary fibrosis: data from the Australian IPF Registry. Respirology. 2017 Jul;22(5):950-6.

15 Jo HE, Glaspole I, Moodley Y, Chapman S, Ellis S, Goh N, et al. Disease progression in idiopathic pulmonary fibrosis with mild physiological impairment: analysis from the Australian IPF registry. BMC Pulm Med. 2018 Jan;18(1):19.

16 Raghu G. Idiopathic pulmonary fibrosis: lessons from clinical trials over the past 25 years. Eur Respir J. 2017 Oct;50(4): 1701209.

17 Paterniti MO, Bi Y, Rekić D, Wang Y, Karimi-Shah BA, Chowdhury BA. Acute exacerbation and decline in forced vital capacity are associated with increased mortality in idiopathic pulmonary fibrosis. Ann Am Thorac Soc. 2017 Sep;14(9):1395-402.

18 Collard HR, Richeldi L, Kim DS, Taniguchi $\mathrm{H}$, Tschoepe I, Luisetti M, et al. Acute exacerbations in the INPULSIS trials of nintedanib in idiopathic pulmonary fibrosis. Eur Respir J. 2017 May;49(5):1601339.

19 Schmidt SL, Tayob N, Han MK, Zappala C, Kervitsky D, Murray S, et al. Predicting pulmonary fibrosis disease course from past trends in pulmonary function. Chest. 2014 Mar;145(3):579-85.

20 Zappala CJ, Latsi PI, Nicholson AG, Colby TV, Cramer D, Renzoni EA, et al. Marginal decline in forced vital capacity is associated with a poor outcome in idiopathic pulmonary fibrosis. Eur Respir J. 2010 Apr;35(4): 830-6.

21 Sharp C, Adamali HI, Millar AB. A comparison of published multidimensional indices to predict outcome in idiopathic pulmonary fibrosis. ERJ Open Res. 2017 Mar; 3(1): 00096-2016.

22 du Bois RM, Weycker D, Albera C, Bradford WZ, Costabel U, Kartashov A, et al. Ascertainment of individual risk of mortality for patients with idiopathic pulmonary fibrosis. Am J Respir Crit Care Med. 2011 Aug; 184(4):459-66.
23 du Bois RM, Albera C, Bradford WZ, Costabel U, Leff JA, Noble PW, et al. 6-Minute walk distance is an independent predictor of mortality in patients with idiopathic pulmonary fibrosis. Eur Respir J. 2014 May;43(5): 1421-9.

24 Vainshelboim B, Kramer MR, Izhakian S, Lima RM, Oliveira J. Physical activity and exertional desaturation are associated with mortality in idiopathic pulmonary fibrosis. J Clin Med. 2016 Aug;5(8):E73.

25 Hook JL, Arcasoy SM, Zemmel D, Bartels MN, Kawut SM, Lederer DJ. Titrated oxygen requirement and prognostication in idiopathic pulmonary fibrosis. Eur Respir J. 2012 Feb;39(2):359-65.

26 Snyder L, Neely ML, Hellkamp AS, O'Brien E, de Andrade J, Conoscenti CS, et al.; IPF$\mathrm{PRO}^{\mathrm{TM}}$ Registry investigators. Predictors of death or lung transplant after a diagnosis of idiopathic pulmonary fibrosis: insights from the IPF-PRO Registry. Respir Res. 2019 May; 20(1): 105 .

27 U.S Food and Drug Administration. The voice of the patient, 2015. Available from: https://www.fda.gov/downloads/ForIndustry/UserFees/PrescriptionDrugUserFee/ UCM440829.pdf. Accessed on 23 April, 2018.

28 Ryerson CJ, Abbritti M, Ley B, Elicker BM, Jones KD, Collard HR. Cough predicts prognosis in idiopathic pulmonary fibrosis. Respirology. 2011 Aug;16(6):969-75.

29 Nishiyama O, Taniguchi H, Kondoh Y, Kimura T, Kato K, Kataoka K, et al. A simple assessment of dyspnoea as a prognostic indicator in idiopathic pulmonary fibrosis. Eur Respir J. 2010 Nov;36(5):1067-72.

30 Kreuter M, Swigris J, Pittrow D, Geier S, Klotsche J, Prasse A, et al. Health related quality of life in patients with idiopathic pulmonary fibrosis in clinical practice: insightsIPF registry. Respir Res. 2017 Jul;18(1):139.

31 Swigris JJ, Stewart AL, Gould MK, Wilson SR. Patients' perspectives on how idiopathic pulmonary fibrosis affects the quality of their lives [in]. Health Qual Life Outcomes. 2005 Oct;3(1):61.

32 Hansell DM, Goldin JG, King TE Jr, Lynch DA, Richeldi L, Wells AU. CT staging and monitoring of fibrotic interstitial lung diseases in clinical practice and treatment trials: a position paper from the Fleischner Society. Lancet Respir Med. 2015 Jun;3(6):483-96.

33 Kim GH, Weigt SS, Belperio JA, Brown MS, Shi Y, Lai JH, et al. Prediction of idiopathic pulmonary fibrosis progression using early quantitative changes on $\mathrm{CT}$ imaging for a short term of clinical 18-24-month followups. Eur Radiol. DOI: 10.1007/s00330-01906402-6.

34 Jacob J, Bartholmai BJ, Rajagopalan S, van Moorsel CH, van Es HW, van Beek FT, et al. Predicting outcomes in idiopathic pulmonary fibrosis using automated computed tomographic analysis. Am J Respir Crit Care Med. 2018 Sep;198(6):767-76.
35 Peljto AL, Zhang Y, Fingerlin TE, Ma SF, Garcia JG, Richards TJ, et al. Association between the MUC5B promoter polymorphism and survival in patients with idiopathic pulmonary fibrosis. JAMA. 2013 Jun;309(21): 2232-9.

36 Jenkins RG, Simpson JK, Saini G, Bentley JH, Russell AM, Braybrooke R, et al. Longitudinal change in collagen degradation biomarkers in idiopathic pulmonary fibrosis: an analysis from the prospective, multicentre PROFILE study. Lancet Respir Med. 2015 Jun; 3(6):462-72.

37 Herazo-Maya JD, Sun J, Molyneaux PL, Li Q, Villalba JA, Tzouvelekis A, et al. Validation of a 52-gene risk profile for outcome prediction in patients with idiopathic pulmonary fibrosis: an international, multicentre, cohort study. Lancet Respir Med. 2017 Nov; 5(11):857-68.

38 Maher TM, Oballa E, Simpson JK, Porte J, Habgood A, Fahy WA, et al. An epithelial biomarker signature for idiopathic pulmonary fibrosis: an analysis from the multicentre PROFILE cohort study. Lancet Respir Med. 2017 Dec;5(12):946-55.

39 Ley B, Ryerson CJ, Vittinghoff E, Ryu JH, Tomassetti S, Lee JS, et al. A multidimensional index and staging system for idiopathic pulmonary fibrosis. Ann Intern Med. 2012 May; 156(10):684-91

40 Wells AU, Desai SR, Rubens MB, Goh NS, Cramer D, Nicholson AG, et al. Idiopathic pulmonary fibrosis: a composite physiologic index derived from disease extent observed by computed tomography. Am J Respir Crit Care Med. 2003 Apr;167(7):962-9.

41 Mura M, Porretta MA, Bargagli E, Sergiacomi G, Zompatori M, Sverzellati N, et al. Predicting survival in newly diagnosed idiopathic pulmonary fibrosis: a 3-year prospective study. Eur Respir J. 2012 Jul;40(1):101-9.

42 Russell AM, Adamali H, Molyneaux PL, Lukey PT, Marshall RP, Renzoni EA, et al. Daily home spirometry: an effective tool for detecting progression in idiopathic pulmonary fibrosis. Am J Respir Crit Care Med. 2016 Oct;194(8):989-97.

43 Johannson KA, Vittinghoff E, Morisset J, Lee JS, Balmes JR, Collard HR. Home monitoring improves endpoint efficiency in idiopathic pulmonary fibrosis. Eur Respir J. 2017 Jul;50(1):1602406.

44 Moor CC, Wapenaar M, Miedema JR, Geelhoed JJ, Chandoesing PP, Wijsenbeek MS. A home monitoring program including realtime wireless home spirometry in idiopathic pulmonary fibrosis: a pilot study on experiences and barriers. Respir Res. 2018 May; 19(1): 105.

45 Cottin V, Hansell DM, Sverzellati N, Weycker D, Antoniou KM, Atwood M, et al. Effect of emphysema extent on serial lung function in patients with idiopathic pulmonary fibrosis. Am J Respir Crit Care Med. 2017 Nov; 196(9):1162-71. 
46 Moor CC, Heukels P, Kool M, Wijsenbeek MS. Integrating patient perspectives into personalized medicine in idiopathic pulmonary fibrosis. Front Med (Lausanne). 2017 Dec; $4: 226$.

47 van Manen MJ, Geelhoed JJ, Tak NC, Wijsenbeek MS. Optimizing quality of life in patients with idiopathic pulmonary fibrosis. Ther Adv Respir Dis. 2017 Mar;11(3):15769.

48 Eakin EG, Resnikoff PM, Prewitt LM, Ries AL, Kaplan RM. Validation of a new dyspnea measure: the UCSD Shortness of Breath Questionnaire. University of California, San Diego. Chest. 1998 Mar;113(3):619-24.

49 Medical Research Council (MRC) dyspnoea scale/MRC breathlessness scale. Available from: https://mrc.ukri.org/documents/pdf/ questionnaire-on-respiratory-symptoms-1986/. Accessed 24 April, 2018.

50 Borg GA. Psychophysical bases of perceived exertion. Med Sci Sports Exerc. 1982;14(5): 377-81.

51 ATS Committee on Proficiency Standards for Clinical Pulmonary Function Laboratories. ATS statement: guidelines for the sixminute walk test. Am J Respir Crit Care Med. 2002 Jul;166(1):111-7.

52 Holland AE, Spruit MA, Troosters T, Puhan MA, Pepin V, Saey D, et al. An official European Respiratory Society/American Thoracic Society technical standard: field walking tests in chronic respiratory disease. Eur Respir J. 2014 Dec;44(6):1428-46.

53 Boehringer Ingelheim International $\mathrm{GmbH}$. Ofev Summary of Product Characteristics. 2018. Available from: http://www.ema.europa.eu/docs/en_GB/document_library/ EPAR_-_Product_Information/human/003821/WC500182474.pdf. Accessed on 16 April, 2018.

54 Roche Registration GmbH. Esbriet Summary of Product Characteristics, 2018. Available from: http://www.ema.europa.eu/docs/ en_GB/document_library/EPAR_-_Product_Information/human/ 002154 / WC500103049.pdf. Accessed 16 April, 2018.

55 Richeldi L, du Bois RM, Raghu G, Azuma A, Brown KK, Costabel U, et al.; INPULSIS Trial Investigators. Efficacy and safety of nintedanib in idiopathic pulmonary fibrosis. N Engl J Med. 2014 May;370(22):2071-82.

56 King TE Jr, Bradford WZ, Castro-Bernardini S, Fagan EA, Glaspole I, Glassberg MK, et al.; ASCEND Study Group. A phase 3 trial of pirfenidone in patients with idiopathic pulmonary fibrosis. N Engl J Med. 2014 May; 370(22):2083-92.

57 Ley B, Swigris J, Day BM, Stauffer JL, Raimundo K, Chou W, et al. Pirfenidone reduces respiratory-related hospitalizations in idiopathic pulmonary fibrosis. Am J Respir Crit Care Med. 2017 Sep;196(6):756-61.
58 Raghu G, Rochwerg B, Zhang Y, Garcia CA, Azuma A, Behr J, et al.; American Thoracic Society; European Respiratory society; Japanese Respiratory Society; Latin American Thoracic Association. An Official ATS/ERS/ JRS/ALAT Clinical Practice Guideline: Treatment of Idiopathic Pulmonary Fibrosis. An Update of the 2011 Clinical Practice Guideline. Am J Respir Crit Care Med. 2015 Jul;192(2):e3-19.

59 Behr J, Günther A, Bonella F, Geißler K, Koschel D, Kreuter M, et al. German guideline for idiopathic pulmonary fibrosis - update on pharmacological therapies 2017. Pneumologie. 2018 Feb;72(2):155-68.

60 Cottin V, Crestani B, Cadranel J, Cordier JF, Marchand-Adam S, Prévot G, et al. French practical guidelines for the diagnosis and management of idiopathic pulmonary fibrosis - 2017 update. Short-length version. Rev Mal Respir. 2017 Oct;34(8):852-99.

61 Funke-Chambour M, Azzola A, Adler D, Barazzone-Argiroffo C, Benden C, Boehler A, et al. Idiopathic pulmonary fibrosis in Switzerland: diagnosis and treatment. Respiration. 2017;93(5):363-78

62 Sköld CM, Bendstrup E, Myllärniemi M, Gudmundsson G, Sjåheim T, Hilberg $\mathrm{O}$, et al. Treatment of idiopathic pulmonary fibrosis: a position paper from a Nordic expert group. J Intern Med. 2017 Feb;281(2):14966.

63 Xaubet A, Molina-Molina M, Acosta O, Bollo E, Castillo D, Fernández-Fabrellas E, et al. Guidelines for the medical treatment of idiopathic pulmonary fibrosis. Arch Bronconeumol. 2017 May;53(5):263-9.

64 Albera C, Costabel U, Fagan EA, Glassberg MK, Gorina E, Lancaster L, et al. Efficacy of pirfenidone in patients with idiopathic pulmonary fibrosis with more preserved lung function. Eur Respir J. 2016 Sep;48(3):84351.

65 Costabel U, Inoue Y, Richeldi L, Collard HR, Tschoepe I, Stowasser S, et al. Efficacy of nintedanib in idiopathic pulmonary fibrosis across prespecified subgroups in INPULSIS. Am J Respir Crit Care Med. 2016 Jan;193(2): $178-85$.

66 Noble PW, Albera C, Bradford WZ, Costabel U, du Bois RM, Fagan EA, et al. Pirfenidone for idiopathic pulmonary fibrosis: analysis of pooled data from three multinational phase 3 trials. Eur Respir J. 2016 Jan; 47(1):243-53.

67 Kolb M, Raghu G, Wells AU, Behr J, Richeldi L, Schinzel B, et al.; INSTAGE Investigators. Nintedanib plus sildenafil in patients with idiopathic pulmonary fibrosis. N Engl J Med. 2018 Nov;379(18):1722-31.

68 Kreuter M, Wuyts W, Renzoni E, Koschel D, Maher TM, Kolb M, et al. Antacid therapy and disease outcomes in idiopathic pulmonary fibrosis: a pooled analysis. Lancet Respir Med. 2016 May;4(5):381-9.
69 Johannson KA, Strâmbu I, Ravaglia C, Grutters JC, Valenzuela C, Mogulkoc N, et al.; Erice ILD Working Group. Antacid therapy in idiopathic pulmonary fibrosis: more questions than answers? Lancet Respir Med. 2017 Jul:5(7):591-8.

70 Weill D, Benden C, Corris PA, Dark JH, Davis $\mathrm{RD}$, Keshavjee S, et al. A consensus document for the selection of lung transplant candidates: 2014-an update from the Pulmonary Transplantation Council of the International Society for Heart and Lung Transplantation. J Heart Lung Transplant. 2015 Jan;34(1):1-15.

71 van Manen MJ, Birring SS, Vancheri C, Cottin V, Renzoni EA, Russell AM, et al. Cough in idiopathic pulmonary fibrosis. Eur Respir Rev. 2016 Sep;25(141):278-86.

72 Kohberg C, Andersen CU, Bendstrup E. Opioids: an unexplored option for treatment of dyspnea in IPF. Eur Clin Respir J. 2016 Mar;3(1):30629.

73 Visca D, Mori L, Tsipouri V, Fleming S, Firouzi A, Bonini M, et al. Effect of ambulatory oxygen on quality of life for patients with fibrotic lung disease $(\mathrm{AmbOx})$ : a prospective, open-label, mixed-method, crossover randomised controlled trial. Lancet Respir Med. 2018 Oct;6(10):759-70.

74 Bell EC, Cox NS, Goh N, Glaspole I, Westall GP, Watson A, et al. Oxygen therapy for interstitial lung disease: a systematic review. Eur Respir Rev. 2017 Feb;26(143):160080.

75 Raghu G, Collard HR, Egan JJ, Martinez FJ Behr J, Brown KK, et al.; ATS/ERS/JRS/ ALAT Committee on Idiopathic Pulmonary Fibrosis. An official ATS/ERS/JRS/ALAT statement: idiopathic pulmonary fibrosis: evidence-based guidelines for diagnosis and management. Am J Respir Crit Care Med. 2011 Mar; 183(6):788-824.

76 Vainshelboim B. Exercise training in idiopathic pulmonary fibrosis: is it of benefit? Breathe (Sheff). 2016 Jun;12(2):130-8.

77 King CS, Nathan SD. Idiopathic pulmonary fibrosis: effects and optimal management of comorbidities. Lancet Respir Med. 2017 Jan; 5(1):72-84

78 Kreuter M, Ehlers-Tenenbaum S, Palmowski $\mathrm{K}$, Bruhwyler J, Oltmanns U, Muley T, et al. Impact of comorbidities on mortality in patients with idiopathic pulmonary fibrosis. PLoS One. 2016 Mar;11(3):e0151425.

79 Bonella F, Wijsenbeek M, Molina-Molina M, Duck A, Mele R, Geissler K, et al. European IPF Patient Charter: unmet needs and a call to action for healthcare policymakers. Eur Respir J. 2016 Feb;47(2):597-606.

80 van Manen MJ, Kreuter M, van den Blink B, Oltmanns U, Palmowski K, Brunnemer E, et al. What patients with pulmonary fibrosis and their partners think: a live, educative survey in the Netherlands and Germany. ERJ Open Res. 2017 Feb;3(1):00065-02016. 
81 Fisher JH, O'Connor D, Flexman AM, Shapera S, Ryerson CJ. Accuracy and reliability of internet resources for information on idiopathic pulmonary fibrosis. Am J Respir Crit Care Med. 2016 Jul;194(2):218-25.

82 Overgaard D, Kaldan G, Marsaa K, Nielsen TL, Shaker SB, Egerod I. The lived experience with idiopathic pulmonary fibrosis: a qualitative study. Eur Respir J. 2016 May; 47(5):1472-80.

83 Ramadurai D, Corder S, Churney T, Graney B, Harshman A, Meadows S, et al. Understanding the informational needs of patients with IPF and their caregivers: 'You get diagnosed, and you ask this question right away, what does this mean?'. BMJ Open Qual. 2018 Jan;7(1):e000207.
84 Wuyts WA, Peccatori FA, Russell AM. Patient-centred management in idiopathic pulmonary fibrosis: similar themes in three communication models. Eur Respir Rev. 2014 Jun;23(132):231-8.

85 Lanken PN, Terry PB, Delisser HM, Fahy BF, Hansen-Flaschen J, Heffner JE, et al.; ATS End-of-Life Care Task Force. An official American Thoracic Society clinical policy statement: palliative care for patients with respiratory diseases and critical illnesses. Am J Respir Crit Care Med. 2008 Apr;177(8): 912-27.
86 Pooler C, Richman-Eisenstat J, Kalluri M. Early integrated palliative approach for idiopathic pulmonary fibrosis: A narrative study of bereaved caregivers' experiences. Palliat Med. 2018 Oct;32(9):1455-64.

87 Mirabelli MC, Preisser JS, Loehr LR, Agarwal SK, Barr RG, Couper DJ, et al. Lung function decline over 25 years of follow-up among black and white adults in the ARIC study cohort. Respir Med. 2016 Apr;113:5764.

88 Kreuter M, Bendstrup E, Russell AM, Bajwah $S$, Lindell K, Adir Y, et al. Palliative care in interstitial lung disease: living well. Lancet Respir Med. 2017 Dec;5(12):968-80. 